\title{
EXTENSÃO UNIVERSITÁRIA E A FORMAÇÃO DE PROFESSORES NO CURSO DE PEDAGOGIA: (DIS) POSIÇÕES PARA ALÉM DAS COMPETÊNCIAS
}

\author{
University extension and teacher education in the pedagogy course: (dis) positions beyond \\ skills \\ Extensión universitaria y formación docente en el curso de pedagogía: (dis) posiciones más \\ allá de las competencias
}

Roberta Pereira de Paula Rodrigues*

Giseli Barreto da Cruz**

https://doi.org/10.38117/2675-181X.formov2021.v3i1n5.165-186

\section{Resumo}

Este artigo se desenvolve em torno de uma pesquisa que teve por objetivo analisar como a participação em ações de extensão universitária, por parte de estudantes de um curso de Pedagogia, pode ser contributiva para o desenvolvimento de (dis) posições para a sua formação docente. Parte do pressuposto que a extensão se situa como componente estratégico para a afirmação de práticas comprometidas com a superação de uma formação para e pelas competências, conforme apregoam as recentes Resoluções do CNE/CP $\mathrm{n}^{\circ}$ 2/2019 e no 1/2020. Teoricamente se sustenta nas ideias de A. Nóvoa e K. Zeichner. Metodologicamente envolve duas etapas qualitativas de trabalho: análise documental e entrevistas. Em torno da primeira etapa, apresentam-se constatações que contribuem para o fortalecimento da defesa a favor de uma formação de professores, no âmbito do curso de Pedagogia, comprometida com a docência em sua complexidade e não, exclusivamente, com as competências necessárias ao seu exercício.

Palavras-chave: Formação de Professores; Curso de Pedagogia; Extensão Universitária. 


\begin{abstract}
This article is developed around a research with the objective of analyzing how the participation in university extension activities of Pedagogy students can contribute to the development of (dis) positions to their teacher education. Starts from the assumption of extension as a strategic component to the affirmation of practices which are committed to overcome an education to and through skills, as proclaimed by recent Resolutions from $\mathrm{CNE} / \mathrm{CP} \mathrm{n}^{\circ} 2 / 2019$ and $\mathrm{n}^{\circ} 1 / 2020$. Theoretically is based on the ideas of A. Nóvoa and K. Zeichner. Methodologically involves two qualitative work steps: documental analysis and interviews. Around the first step findings are presented which contribute to strengthen the defense in favor of a teacher education, in the context of the Pedagogy course, committed to teaching in its complexity and not, exclusively, to the skills needs in its practice.
\end{abstract}

Keywords: Teacher Education; Pedagogy Course; University Extension.

\title{
Resumen
}

Este artículo se desarrolla en torno a una investigación que tuvo como objetivo analizar cómo la participación en acciones de extensión universitaria, por parte de estudiantes de un curso de Pedagogía, puede contribuir al desarrollo de (des) posiciones para su formación docente. Se parte del supuesto de que la extensión es un componente estratégico para la afirmación de prácticas comprometidas con la superación de la formación por y por competencias, como se proclama en las recientes Resoluciones CNE/CP 2/2019 y CNE/CP1/2020. Teóricamente se basa en las ideas de A. Nóvoa y K. Zeichner. Metodológicamente se trata de dos pasos de trabajo cualitativos: análisis de documentos y entrevistas. En torno a la primera etapa se presentan hallazgos que contribuyen al fortalecimiento de la defensa a favor de la formación docente, en el ámbito del curso de Pedagogía, comprometidos con la enseñanza en su complejidad y no exclusivamente con las competencias necesarias para su desarrollo.

Palabras clave: Formación de profesores; Curso de Pedagogía; Extensión Universitaria.

\section{Introdução}

Este artigo tem como ponto de partida uma pesquisa sobre a participação da extensão universitária na formação de professores, no âmbito do curso de Pedagogia, considerando especialmente as (dis) posições para a profissão. Como a participação em ações extensionistas pode contribuir para firmar a posição do professor em formação em uma docência comprometida com fazeres e saberes pedagógicos dialógicos e culturalmente sustentados? Como a extensão pode contribuir para uma prática docente promotora de diálogo com a comunidade e a sociedade? Como a Extensão Universitária 
pode contribuir para o desenvolvimento das (dis) posições para a formação docente, no âmbito do curso de Pedagogia?

Tais questionamentos nos dirigem para dois cenários. De um lado, o cenário da extensão universitária, iniciada nas universidades do Brasil em 1911 e presente em documentos oficiais orientadores do ensino superior desde a década de 1960. Como um dos elos constitutivos de uma universidade, a extensão assume a responsabilidade pelo processo educativo, cultural e científico de articulação dos demais elos - o ensino e a pesquisa - entre a universidade e a sociedade.

Historicamente, a extensão, apesar de seu escopo institucional vinculado aos espectros comunitário e social, teve a sua prática efetiva muito mais situada em um lugar no qual a posição da universidade estava verticalmente superior à posição da sociedade, representada pela comunidade extramuros. Em 1987, com a criação do Fórum Nacional de Pró-Reitores de Extensão das Universidades Públicas Brasileiras (FORPROEX), o conceito de extensão universitária foi estabelecido com a utilização de palavras e expressões como "via de mão dupla", "relação transformadora", "troca de saberes", e "processo dialético de teoria/prática", que seriam determinantes para que a relação universidade-comunidade fosse estabelecida de uma maneira mais dialógica e horizontal (FORPROEX, 1987).

Segundo o Plano Nacional de Extensão Universitária (2001), esta dimensão da formação acadêmica é um dos pilares da Educação Superior, e sua participação na universidade se dá na formação profissional em articulação com o ensino e a pesquisa, de forma que possibilite, mediante suas ações, um caminho de transformação da sociedade brasileira em direção à justiça, à solidariedade e à democracia, pois que: "Além de instrumentalizadora deste processo dialético de teoria/prática, a extensão é um trabalho interdisciplinar que favorece a visão integrada do social" (FORPROEX, 1987, p. 11). Nessa direção, nos alinhamos com a concepção de extensão inscrita na defesa de Souza (2010), a saber:

[...] a Extensão pode também assumir o papel de instrumento de emancipação, de desenvolvimento das capacidades humanas. Isso acontece quando sua prática é transformadora, na medida em que provoca rupturas e pode ser identificada como uma práxis revolucionária, como "prática da liberdade" (SOUZA, 2010, p.126).

De outro lado, temos o cenário da formação docente no âmbito do curso de Pedagogia, conforme definem as suas diretrizes curriculares específicas, ainda vigentes, promulgadas no ano de 2006 pelo Conselho Nacional de Educação (CNE). O seu horizonte está na preparação profissional para atuação na Educação Infantil e nos anos 
iniciais do Ensino Fundamental; nos cursos de Ensino Médio, na modalidade Normal; em cursos de Educação Profissional na área de serviços e apoio escolar e em áreas nas quais sejam previstos conhecimentos pedagógicos. A formação prevista abrange integradamente à docência a participação na gestão e avaliação de sistemas e instituições de ensino em geral, a elaboração, a realização, o acompanhamento de programas e as atividades educativas em contextos escolares e não escolares. Um princípio fundante da formação em tela reside na dimensão teórico-prática para o exercício integrado e indissociável da docência, da gestão dos processos educativos escolares e não escolares e, ainda, da produção e difusão do conhecimento científico e tecnológico do campo educacional, cuja teorização e construção da prática educativa constituem o objeto da Pedagogia.

Há quase duas décadas o curso de Pedagogia no Brasil se orienta por essas diretrizes, que se, por um lado, contribuíram para afirmar a necessidade da docência como base da formação, por outro, ajudaram a dispersar a formação do pedagogo em relação àquilo que constitui a Pedagogia como uma área epistemologicamente inscrita e delimitada no campo teórico-prático da Educação. Por essa via, formar professores no curso de Pedagogia para atuação em diferentes etapas da educação básica e nas suas mais variadas modalidades, sem desconsiderar as diversas possibilidades do trabalho do pedagogo na escola e fora dela, tem exigido das instituições formadoras comprometidas com a preparação do profissional pedagogo um esforço de integralização curricular e de parceria institucional.

Cumpre aqui salientar que um aspecto do curso de Pedagogia que tem chamado especial atenção diz respeito ao crescimento de sua oferta na modalidade EAD. De acordo com dados do Censo do Ensino Superior (INEP, 2017), a EAD tem apresentado um crescimento exponencial, visto que, enquanto o número de matrículas em curso de graduação diminuiu 0,4\% entre 2016 e 2017, na modalidade a distância, esse número aumentou 17,6\% no mesmo período. No decorrer de uma década - 2007 a 2017 - as matrículas nos cursos de graduação EAD aumentaram 375,2\%, enquanto a presencial registrou 33,8\%. Esse aspecto afeta frontalmente o curso de Pedagogia, cuja oferta massiva não tem sido cuidada pela instituição universitária, comprometida com o ensino, a pesquisa e a extensão, mas, predominantemente, pelas instituições de ensino superior privadas, sem vocação universitária, e, ainda, com forte apelo à modalidade $\mathrm{EaD}$.

Esse contexto controverso de formação do pedagogo percebe-se ainda mais afrontado recentemente com a aprovação da Base Nacional Comum Curricular para a Educação Básica/BNCC (BRASIL, 2017). A formação de professores se vê espraiada em um campo de disputas sobre o que conta como educação, ensino, docência e, 
consequentemente, formação. Nutrida por uma visão reformista de educação, em uma abordagem economicista de viés tecnicista, a formação docente requerida pela BNCC tem na noção de competências o seu principal eixo curricular e na instituição de ensino superior privada, sem a marca universitária, sua principal parceira.

Nessa direção, são promulgadas, de forma aligeirada e sem consideração ao debate prevalecente na área, as Diretrizes Curriculares Nacionais para a Formação Inicial de Professores para a Educação Básica acompanhadas da Base Nacional Comum para a Formação Inicial de Professores, ambas instituídas na Resolução CNE/CP n. 2/2019, e as Diretrizes Curriculares Nacionais para a Formação Continuada de Professores da Educação Básica com a Base Nacional Comum para a Formação Continuada de Professores da Educação Básica, fixadas pela Resolução CNE/CP nº 1/2020.

Nesse contexto, a formação do pedagogo no Brasil, com as diretrizes curriculares de 2006, se vê alojado em um curso de licenciatura orientado do ponto de vista legal, segundo discute Pereira (2014), para ser flexível, de modo a incorporar conhecimentos, saberes e competências compatíveis com uma formação centrada no mundo do trabalho, valorizando uma formação pragmática, pouco investida nos fundamentos teóricos. Com as diretrizes curriculares para a formação inicial e continuada docente, esse aspecto se sobreleva, com vistas a garantir as mudanças na educação, impostas pelas agências governamentais compromissadas com o projeto neoliberal em voga.

Diante disso, mais que nunca, é mister investir em práticas formativas comprometidas com a superação de uma formação para e pelas competências. Nesse esforço de superação, situa-se a compreensão que rege a aposta da pesquisa em tela, que tem na Extensão Universitária, na sua condição intrínseca de componente curricular instituído, uma via contributiva ao desenvolvimento das (dis) posições para a formação docente, no âmbito do curso de Pedagogia.

\section{Concepções de formação: entre as competências e a docência}

A vinculação entre educação e mercado, fortemente marcada pelo conceito de competências presente nos marcos regulatórios para a formação inicial e continuada de professores - CNE/CP n ${ }^{\circ}$ 2/2019 e CNE/CP n $1 / 2020$, fundamenta-se em um conjunto de teorias curriculares instrumentais, com forte viés comportamentalista e padronizador, conforme apontam Dias e Lopes (2003). O enfoque das competências incide sobre uma concepção de formação docente restrita à compreensão do ensino como ato de aplicação de conteúdo. Como discutido por Diniz-Pereira (2021), estes documentos contribuem 
para delimitar uma formação docente circunscrita aos processos da sala de aula, compreendendo a dimensão da prática como um saber-fazer ancorado em um pragmatismo e utilitarismo técnico-instrumental que relega a teoria ao segundo plano, em um retorno à tentativa de padronização dos currículos dos cursos de licenciatura.

Desse modo, acentua-se uma concepção, conforme discute Pérez Gómes (1998), que posiciona a prática profissional do professor de maneira distanciada da complexidade da situação social. Tal concepção de cunho aplicacionista, baseada na valorização da dimensão técnica, altamente restritiva da autonomia docente, da criatividade e capacidade intelectual e política dos professores, está alinhada com a defesa de que as mudanças na educação dependem de mudanças na formação de professores aliadas a metas de controle do trabalho docente, fortalecendo políticas de avaliação por desempenho, promoção por mérito, produtividade, eficiência e eficácia, como forma de atender às exigências mercadológicas.

Compreendemos, tal qual Portelinha (2021), que estas resoluções ao incorporarem uma racionalidade formativa cujo centro está pautado em competências e habilidades contribui para dissociar a formação do trabalho e traz à tona duas questões nucleares que se desdobram no curso de Pedagogia: a relação que se estabelece entre teoria e prática e a fragmentação do percurso formativo inicial e continuado. Sobre a dimensão teóricoprática da formação docente destacamos o papel da concepção dialética que, em contraposição à separação e hierarquização entre teoria e prática apresenta o tensionamento estre ambas, reconhecendo a unidade dos termos.

Ao reconhecer a Extensão Universitária como mediadora do processo dialético de teoria/prática, bem como uma via interdisciplinar e interprofissional de formação, além de indissociável da pesquisa e do ensino e marcada por uma relação transformadora entre universidade e sociedade por meio de vivências coletivas e contingentes, acreditamos que sua concepção e prática encontram aproximações com princípios que demarcam um rompimento com a "Pedagogia da Competência". Estes princípios, podem ser traduzidos por: unidade entre teoria e prática, a centralidade do trabalho como princípio educativo, a pesquisa como princípio cognitivo e formativo, o compromisso social, político e ético com um projeto emancipador e transformador das relações sociais, e a vivência do trabalho coletivo e interdisciplinar de forma problematizadora.

Diferentemente deste atual cenário da formação construído pelos recentes marcos regulatórios, as concepções de formação de professores que defendemos como aporte para a condução de ações direcionadas a prepará-los para atuarem mediante as necessidades da sociedade atual, situam-se a favor do desenvolvimento de uma docência comprometida com a justiça social e os princípios democráticos, conforme as ideias 
disseminadas nos trabalhos de Zeichner (2010), Zeichner et al (2014, 2015) e Nóvoa $(2009,2017)$. São concepções que se entrelaçam ao redor de uma perspectiva de formação docente orientada para uma relação horizontalmente constituída entre universidade, escola e comunidade, na qual a cultura profissional, a postura investigativa e a valorização dos saberes socialmente construídos são constitutivas de um novo lugar institucional responsável por formar o professor.

Zeichner (2010) aponta para o trabalho de formadores que há muitos anos vem contribuindo na defesa da ampliação do lócus da formação inicial para as comunidades em um sentido tanto de aproximação dos futuros professores com a comunidade para estabelecer, manter e afirmar uma relação presente e fundamental entre educação, ensino, aprendizagem e sociedade, quanto num sentido de reconhecer, utilizar e valorizar o saber proveniente dessa comunidade. $\mathrm{O}$ caminho para a mudança exige, portanto, uma nova posição da universidade quanto ao seu papel na formação de professores, na construção do conhecimento e na relação com as escolas e com as comunidades. As experiências que já existem nas escolas passam a ocupar um lugar chave, no qual o conhecimento construído nessas experiências é reconhecido como parte importante para a formação inicial do professor.

Então, faz-se necessário pensar cuidadosamente nos objetivos e propósitos da formação de professores, para que esta não incorra no erro de tender mais ao treinamento do que à formação propriamente (LISTON \& ZEICHNER, 1991, p. 37). Para tal, todas as ações presentes no percurso formativo do professor são exigentes de planejamento cuidadoso que o posicionem, sendo o mesmo experiente, iniciante ou ainda estudante, de uma maneira na qual a reflexão e a participação ocupem o espaço da reprodução e da aplicação. Trata-se, pois, de uma concepção que se contrapõe frontalmente aquela que sustenta os marcos regulatórios vigentes para a formação de professores que intencionam dirigir o conhecimento e a prática docentes por um caminho marcado pela constituição de competências e habilidades.

Tomamos como base a compreensão da extensão universitária tanto enquanto um processo que promove a interação transformadora entre universidade e outros setores da sociedade (FORPROEX, 2010), como enquanto uma ação comprometida com a construção do conhecimento pela dialogicidade (FREIRE, 2006). Nesse confronto entre as concepções de formação, consideramos a extensão universitária como uma via estratégica para posicionar intencionalmente professores em formação inicial em uma relação dialógica com a comunidade, numa relação horizontalmente estabelecida pelo reconhecimento e valorização do conhecimento e experiências construídas nas escolas, 
de maneira participativa e refletida, conformando-se, assim, como importante aliada para superar as consequências de uma formação orientada pelas competências.

Na mesma direção, recorremos a Nóvoa (2009) para defender que a relação entre a universidade, as escolas, os professores e a sociedade carece de ser caracterizada pela presença da reflexão sobre o próprio trabalho docente, ou seja, os dilemas da profissão servirão como base para a construção de teorias capazes de fornecer respostas às perguntas que desafiam a realidade do trabalho do professor na contemporaneidade. Para tal, a colegiabilidade, a partilha, e as culturas colaborativas entre professores, escolas, universidades e poder público se fazem de fundamental importância para que uma maior autonomia no trabalho docente seja alcançada e fortalecida, diminuindo também o afastamento entre a formação e a profissão (NÓVOA, 2017). Opostamente, a concepção de competências que dá enfoque na aplicabilidade e na dimensão técnica e comportamentalista do fazer profissional parece não permitir uma aproximação com a complexidade da docência e das inúmeras questões que marcam os dilemas dessa profissão. Em contraposição ao conceito de "competências", Nóvoa (2009) propõe a noção de "disposições" como alternativa mais fluida e capaz de articular as dimensões pessoais e profissionais do professor. Para o autor, são essenciais à formação inicial docente: 1. Disposição para o conhecimento; 2. Disposição para a cultura profissional; 3. Disposição para o tato pedagógico; 4. Disposição para o trabalho em equipe; 5. Disposição para o compromisso social.

Em artigo mais recente, Nóvoa (2017) retoma essa discussão de uma forma mais ampliada a partir do conceito de posições. $\mathrm{O}$ autor utiliza-se da riqueza de significados do termo posição para representar cinco entradas para pensar a formação profissional de professores. Enquanto postura, essa entrada relaciona-se com a construção de uma atitude pessoal dentro da profissão. Enquanto condição, refere-se ao desenvolvimento de um lugar no interior da profissão. Enquanto estilo, direciona-se para a criação de uma maneira particular de agir e organizar seu trabalho. Enquanto arranjo, ou rearranjo, marca a capacidade de, permanentemente, encontrar novas maneiras de atuar. Enquanto opinião, caracteriza uma forma de intervenção e afirmação da profissão, publicamente. Utilizando-se das dimensões desse conceito, o autor defende sua proposta de formação de professores, enquanto formação universitária, que considere cinco entradas, que não são apenas disposições, mas também uma interposição, uma composição, uma recomposição e uma exposição. Dessa maneira, demarca mais claramente o seu pensamento contrário à premissa de que existam características definitórias para a profissão docente, e coloca-se mais próximo ao conceito de habitus de Bourdieu, quando declara que "por essa via, afasta-se de uma visão determinista para se colocar num campo 
de forças e de poderes em que cada um constrói a sua posição em relação consigo mesmo e com os outros" (NÓVOA, 2017, p. 1119).

$\mathrm{Na}$ esteira do pensamento desses autores, pressupomos que as atividades de extensão universitária, dada a sua condição de elo de ligação entre universidade e sociedade por meio de um processo orgânico e integrado de educação, cultura e ciência, apresentam condições de proporcionar experiências formativas que articulem formação inicial, indução e formação em serviço de maneira que seu processo esteja amparado na investigação, colaboração, trabalho em equipe e acompanhamento. Destacamos que estes autores não se relacionam diretamente com a ação extensionista, mas sim com a formação docente. No entanto, suas escolhas se justificam por se colocarem no rol dos estudiosos que sinalizam em seus trabalhos que a docência deve romper com os modelos de formação inicial e continuada centrados na racionalidade técnica, e devem primar por um trabalho de reflexividade sobre as práticas e de uma (re)construção permanente de uma identidade (ZEICHNER, 1993; NÓVOA, 1995).

Assim, defendemos que a formação de professores precisa ser compreendida e praticada a partir de uma concepção que não apenas se distancie do conceito mercadológico, tecnicista, padronizado e pragmático de competências, mas que aponte para uma perspectiva onde o diálogo, a reflexão e a colaboração entre escolas, comunidades, professores e universidades seja a base fundante da formação inicial dos professores, em estreita relação com a formação continuada dos profissionais da educação e a valorização profissional. Baseadas nessa defesa, buscamos lançar nosso olhar para a extensão universitária como uma aliada estratégica.

\section{Aspectos metodológicos}

Tomando por base a concepção de docência aludida na seção anterior, realizamos uma pesquisa qualitativa com o objetivo de compreender como a participação em ações de extensão universitária, por parte de estudantes de um curso de Pedagogia, pode ser contributiva para o desenvolvimento de (dis) posições para sua formação docente. $\mathrm{O}$ campo de pesquisa foi delimitado em torno de uma IES pública federal localizada no estado do Rio de Janeiro. O trabalho metodológico foi organizado em duas etapas, sendo uma com foco nos documentos e outra com foco nos depoimentos dos sujeitos envolvidos com as ações de extensão.

A primeira etapa teve como fonte os dados da extensão gerados pelo Sistema de Informação e Gestão de Projetos — SIGProj e como ferramenta metodológica a análise 
documental dos registros das ações de extensão, materializadas nas informações sobre os programas, projetos, cursos e eventos de extensão institucionalizados e protocolados referido sistema sob as denominações de "proposta ${ }^{1}$ recomendada em andamento" 2 e "proposta recomendada concluída". Essa etapa teve por objetivo conhecer os processos que se articulam desde a proposição até o registro dessas ações, e compreender, na perspectiva dos documentos de registro de ações de extensão, como se dá sua contribuição para o desenvolvimento das (dis) posições para a formação docente.

Na segunda etapa, com os dados refinados, foi possível localizar os sujeitos, dentre docentes, técnicos e discentes, envolvidos com a realização dessas ações e com o curso de Pedagogia, para entrevistá-los e analisar seus depoimentos. Portanto, com base na análise feita na primeira etapa da pesquisa, pudemos definir a composição da segunda fonte para a construção de dados, que possibilitou compreender a contribuição da participação da extensão no desenvolvimento das (dis) posições para a formação docente, no contexto do curso de Pedagogia da IES investigada.

No contorno deste artigo, nos deteremos exclusivamente na primeira etapa da pesquisa, orientada pelo objetivo de compreender, na perspectiva dos documentos de registro de ações de extensão, como se dá sua contribuição para o desenvolvimento das (dis) posições para a formação docente.

À guisa de contextualização, pontuamos que o sistema SIGProj pode gerar planilhas que consolidam os dados registrados em sua base. Desta forma, a consolidação desses dados pode ser gerada de maneira que a organização das informações obedeça a intenções aplicadas a partir da utilização de alguns filtros de busca. São ao todo 16 possibilidades de filtros que podem ser aplicados individualmente ou de forma combinada. Assim sendo, percebemos que as informações essenciais para a análise se encontravam disponíveis para consulta, o que faz com que esses registros utilizados possam ser classificados como dados secundários, que segundo Mattar (1996, p. 48), "são

\footnotetext{
1 Todos os registros são classificados como PROPOSTA, visto que, inicialmente, o proponente cadastra as informações sobre a ação em um formulário específico e detalhado por modalidade, e as informações contidas nesse formulário serão avaliadas por técnicos e docentes em diferentes instâncias acadêmicas tanto da unidade à qual o proponente pertence, quanto do centro e da PR5. Mesmo após o processo de avaliação e a aprovação da ação como uma ação extensionista institucionalizada o sistema mantém a nomenclatura PROPOSTA, porém ela passa de REGISTRADA para RECOMENDADA.

2 Das propostas recomendadas levantadas, esta pesquisa se propôs a observar as que estavam classificadas como propostas recomendadas EM ANDAMENTO, ou seja, em período de realização; e CONCLUÍDAS, ou seja, que finalizaram sua realização. Algumas outras classificações como CANCELADA e ARQUIVADA não foram consideradas, porque eram referentes a ações que não aconteceram ou que tiveram problemas e não foram concluídas.
} 
aqueles que já foram coletados, tabulados, ordenados e, às vezes, até analisados e que estão catalogados à disposição dos interessados".

Inicialmente, observando todos os registros disponíveis no sistema, obtivemos informações sobre um total de 4.259 ações. A partir de um filtro que considerou um limite temporal e a validade desses registros, esse número foi reduzido para 2.002. O segundo passo consistiu em aplicar alguns critérios de seleção capazes de relacionar, dentre as 2.002 ações extensionistas, somente aquelas que demonstrassem um direcionamento para a formação de professores. Nesse sentido, fizemos um tratamento da base de dados que isolou, do total inicial, apenas as ações que estavam de acordo com os seguintes critérios: pertenciam à área temática da Educação; possuíam as expressões "formação de professores", "formação docente", e/ou "formação continuada" dentre as palavras-chaves relacionadas; possuíam escolas de ensino básico na descrição de seus locais de realização; e professores da educação básica como público-alvo na definição de seus registros.

A Pró-Reitoria de Extensão da IES investigada orienta que ações sejam propostas nas modalidades: projeto, curso e evento, definidas da seguinte forma:

- Projeto: ação processual e contínua, de caráter educativo, social, cultural ou tecnológico, com objetivo específico, prazo determinado de no mínimo 12 meses de execução e que responda à totalidade das diretrizes da extensão;

- Curso: ação pedagógica de caráter teórico e/ou prático, presencial ou a distância, planejada e organizada de modo sistemático, com carga horária mínima de oito horas e critérios de avaliação definidos institucionalmente;

- Evento: ação institucional de caráter eventual classificada quanto ao interesse, número de participantes e metodologia, que implica na apresentação e/ou exibição pública e troca livre de conhecimento ou produto cultural, artístico, esportivo, científico e tecnológico desenvolvido, conservado ou reconhecido no âmbito da extensão universitária ou que pretenda convocar a comunidade externa a desenvolver ações de extensão. Essa ação deve ser voltada a um público-alvo majoritariamente e prioritariamente externo à IES.

Havia na IES, portanto, uma política em curso que não previa o registro de novos programas de extensão. Desta maneira, o levantamento evidenciou uma grande representatividade de ações pontuais nas modalidades acima citadas. Contudo, acreditando que as ações contínuas e que respondem à totalidade das diretrizes da extensão permitiriam uma aproximação mais potente com as perspectivas das disposições 
e posições para a formação docente (NÓVOA, 2009, 2017), consideramos concentrar nosso olhar apenas sobre os programas de extensão ainda ativos e os projetos de extensão.

Partimos então para a análise desses documentos. Com a leitura dos formulários de registro que sintetizam as propostas dos programas e projetos mapeados, a análise do conteúdo organizou-se de forma a buscar indícios do desenvolvimento das (dis) posições, a partir de categorias.

\section{(Dis)posições para a formação docente em programas e projetos de extensão universitária}

A partir do ano de 2014 consolida-se o uso do SIGProj para registro das ações de extensão, o que coincide com o início da articulação da comunidade acadêmica para a curricularização da extensão nos cursos de graduação. Por esse motivo, e para fins desta pesquisa, escolheu-se trabalhar a partir das propostas recomendadas submetidas no período filtrado pelo sistema entre 01/01/2014 e 31/12/2019, já que, com o uso do sistema consolidado pela equipe técnica da universidade, esses dados revelam mais veracidade em suas informações armazenadas.

A primeira rodada de levantamento dos dados permitiu constatar que a área temática com maior representação nas ações de extensão registradas na universidade, em todas as modalidades, é Educação, com um total de 687 ações entre programas, projetos, cursos e eventos em andamento e concluídos. Esse número diante do universo de 2.002 registros válidos representa mais de $34 \%$ do total. Essa característica certamente demonstra uma atuação marcante da IES no campo da Educação não somente mediante o ensino e a pesquisa, como também da extensão universitária.

A partir da identificação do panorama das diferentes áreas temáticas, o passo seguinte foi concentrar a pesquisa na área da Educação. A estratégia usada para extrair dessa área, que entre ações em andamento e concluídas soma 687 registros, apenas os resultados que revelem aquelas com direcionamento para a formação de professores, foi a identificação das palavras-chaves FORMAÇÃO CONTINUADA, FORMAÇÃO DE PROFESSORES ou FORMAÇÃO DOCENTE dentre as cadastradas. Essa escolha foi feita baseada na aposta de que a ação que se volta para as comunidades incorporando como uma das questões-chaves a formação de professores, teria maior direcionamento para relacionar essa questão com a formação inicial dos pedagogos docentes participantes de sua realização. 
Assim, considerando apenas a área temática Educação e as modalidades de projetos, cursos e eventos ${ }^{3}$ que em seus registros apresentavam com as palavras-chaves escolhidas, obteve-se o seguinte quadro:

Quadro 1 - Quantitativo de ações em andamento e concluídas com as palavras-chaves

\begin{tabular}{|c|c|c|c|c|}
\hline \multicolumn{5}{|c|}{$\begin{array}{c}\text { AÇÕES DA ÁREA DE EDUCAÇÃO COM PALAVRAS-CHAVES: FORMAÇÃO } \\
\text { CONTINUADA, FORMAÇÃO DE PROFESSORES OU FORMAÇÃO DOCENTE }\end{array}$} \\
\hline \multirow{2}{*}{ MODALIDADE } & \multicolumn{3}{|c|}{ EM ANDAMENTO } & \multicolumn{2}{c|}{ CONCLUÍDO } \\
\cline { 2 - 5 } & TODOS & PALAVRA-CHAVE & TODOS & PALAVRA-CHAVE \\
\hline PROGRAMAS & 3 & 2 & 0 & 0 \\
\hline PROJETOS & 208 & 20 & 77 & 7 \\
\hline CURSOS & 85 & 9 & 201 & 27 \\
\hline EVENTOS & 38 & 5 & 75 & $\mathbf{4 1}$ \\
\hline TOTAL & $\mathbf{3 3 4}$ & $\mathbf{3 6}$ & $\mathbf{3 5 3}$ & 7 \\
\hline
\end{tabular}

Fonte: elaboração própria.

Debruçamo-nos analiticamente sobre os números levantados para compreender como está a representação da formação de professores na extensão universitária a partir do critério selecionado das palavras-chaves, sendo possível constatar que nas diversas modalidades de ações em andamento e concluídas encontram-se diferentes resultados.

Os programas em andamento que se inscrevem na área temática da Educação optaram por palavras-chaves que não são exatamente as escolhidas como critérios nesta pesquisa, porém notamos que apresentam aproximações relevantes. O Programa Integrado para Educação de Jovens e Adultos utilizou na descrição de sua proposta de ação as palavras-chaves: Educação de Jovens e Adultos - Formação - Extensão Universitária. O Programa Articulado Complexo de Formação Continuada para Profissionais da Educação Básica utilizou as palavras-chaves: Educação Básica Professores - Educacional — Formação continuada. No entanto, o programa Cinema para aprender e desaprender ao utilizar as palavras-chaves: Cinema - Educação Escola - Abecedários, não demonstrou, pelos critérios estabelecidos, a marcação do campo de formação de professores como questão relevante de sua realização. Todavia,

3 Os programas são formas de organização das ações de extensão. Um programa pode ter várias modalidades de ações vinculadas a ele. Portanto, os projetos, cursos e eventos de extensão localizados, já fazem parte dos programas identificados previamente. 
em se tratando de um programa da área da educação que tem desenvolvido suas ações considerando a escola como lócus, optamos por mantê-lo dentro do corpus de análise.

Das demais modalidades de ações em andamento, foi possível verificar que os eventos têm maior representatividade com as palavras-chaves Formação de professores, Formação docente e/ou Formação continuada em relação ao total de eventos em educação, demonstrando que $13,16 \%$ do total de 38 mencionaram uma ou mais das palavras-chaves.

Em seguida, observamos os resultados dos cursos, que demonstraram que 10,58\% do total de 85 cursos fez tal menção, e por fim os projetos, nos quais 9,61\%, considerando um total de 208, listaram uma ou mais das palavras-chaves em suas propostas de execução.

Quanto às ações concluídas vimos que os cursos têm maior representatividade das palavras-chaves, demonstrando que 13,93\% do total de 201 cursos mencionou Formação de professores, Formação docente e/ou Formação continuada como palavras-chaves.

Os eventos demonstraram que $10,66 \%$ do total de 75 fez tal menção, e por fim os projetos revelaram que $9,09 \%$ de um total de 77 listaram uma ou mais das palavras-chaves em suas propostas de execução.

Apesar de observarmos que na modalidade de projetos o direcionamento para a formação de professores, considerando os critérios de palavras-chaves por nós adotados, não é foi o maior entre as modalidades, escolhemos delimitar nosso campo de investigação a esse tipo de ação e aos programas. Nossa escolha ancora-se no fato dos projetos serem a única modalidade que obrigatoriamente deve contemplar todas as diretrizes da extensão em suas propostas, e em reflexões feitas ao longo do nosso estudo a partir de relações que estabelecemos entre as diretrizes da extensão universitária e as disposições de Nóvoa (2009).

Neste sentido, optamos por observar mais atentamente, além dos programas ainda ativos, os projetos de extensão que se propõe propunham a acontecer em escolas e que têm como público-alvo os professores da educação básica, a fim de marcarmos a participação das escolas e seus professores nesse processo dialógico engendrado pela atividade extensionista, principalmente no que se refere ao seu potencial para o desenvolvimento não somente das disposições, mas também das posições para a formação docente, relacionadas com as perguntas apresentadas por Nóvoa (2017). Adotamos esse critério como forma de reiterar o papel estratégico da extensão universitária enquanto propiciadora de colaboração entre professores da educação básica 
e professores universitários, favorecendo relações entre universidade e escola básica mais permeáveis e imbricadas.

Os programas institucionais identificados foram:

1. Programa Integrado para Educação de Jovens e Adultos;

2. Programa Articulado Complexo de Formação Continuada para Profissionais da Educação Básica;

3. Cinema para aprender e desaprender.

Foi possível relacionar oito projetos de extensão dentro da área temática da Educação, que utilizaram as palavras-chaves Formação de professores, Formação docente e/ ou Formação continuada, cujas propostas apresentavam escolas de educação básica como locais de realização e professores da educação básica como público-alvo de seus objetivos. Foram eles:

1. Conversas entre professores: alteridades e singularidades - Este projeto faz parte do Programa Articulado Complexo de Formação Continuada para Profissionais da Educação Básica;

2. Debates em Educação - Região Serrana - Este projeto faz parte do Programa Articulado Complexo de Formação Continuada para Profissionais da Educação Básica;

3. Educação Física na perspectiva inclusiva 2018 - Este projeto faz parte do Programa Articulado Educação Pública, Formação Permanente e Educação Popular;

4. Formação de Professores da Educação Infantil - entre práticas e propostas pedagógicas - Este projeto faz parte do Programa Articulado Educação Pública, Formação Permanente e Educação Popular;

5. Núcleo de atividades de iniciação à docência: formação de professores no espaço escolar - Este projeto faz parte do Programa Articulado Educação Pública, Formação Permanente e Educação Popular;

6. Formação de professores: infância, adolescência e mal-estar na escolarização - Este projeto faz parte do Programa Articulado Educação Pública, Formação Permanente e Educação Popular;

7. O trabalho com imagem e texto na educação contemporânea - Este projeto faz parte do Programa Articulado Expressões e Linguagens: Saberes em Movimento;

8. Águas no planejamento municipal: discutindo a educação ambiental na gestão de bacias hidrográficas no médio vale do Rio Paraíba do Sul e na Região 
Metropolitana do Rio de Janeiro - Este projeto faz parte do Programa Articulado Educação Pública, Formação Permanente e Educação Popular.

A análise documental foi realizada com base nos resumos, justificativas, objetivos e descrições metodológicas das propostas e levando em conta as categorias prévias construídas, segundo as (dis) posições apresentadas por Nóvoa (2017), tal como observadas no quadro $\mathrm{n}^{\circ} 2$.

Quadro 2 - Categorias de análise

\begin{tabular}{|c|c|}
\hline Posições & Aspectos fundamentais / Categorias \\
\hline \multirow{4}{*}{ Disposição Pessoal } & $\begin{array}{c}\text { Conhecer as motivações, o perfil, a predisposição para a profissão } \\
\text { docente }\end{array}$ \\
\hline & Dar um primeiro conhecimento da profissão \\
\hline & Verificar se tem as condições e predisposições para ser professor \\
\hline & $\begin{array}{l}\text { Oferecer espaços e tempos de autoconhecimento e autoconstrução para } \\
\text { que uma predisposição se transforme em uma disposição pessoal }\end{array}$ \\
\hline \multirow{3}{*}{$\begin{array}{l}\text { Interposição } \\
\text { Profissional }\end{array}$} & Presença de outros professores \\
\hline & Vivência das instituições escolares \\
\hline & Reconhecer o papel e a função formadora dos professores das escolas \\
\hline \multirow{3}{*}{$\begin{array}{l}\text { Composição } \\
\text { Pedagógica }\end{array}$} & Encontrar sua maneira de ser professor, com outros professores \\
\hline & Valorizar o conhecimento profissional de outros professores \\
\hline & $\begin{array}{l}\text { Julgar e decidir no dia a dia profissional lidando com o conhecimento em } \\
\text { situações de relação humana }\end{array}$ \\
\hline \multirow{3}{*}{$\begin{array}{l}\text { Recomposição } \\
\text { Investigativa }\end{array}$} & Incorporar na rotina da profissão uma dinâmica de pesquisa \\
\hline & Analisar sistematicamente o trabalho em colaboração com os colegas \\
\hline & Registrar reflexões, acumular conhecimentos e renovar práticas \\
\hline \multirow{4}{*}{ Exposição Pública } & Desenvolver consciência crítica \\
\hline & Participar na construção de políticas públicas \\
\hline & Proporcionar espaços de expressão das diferenças e deliberação conjunta \\
\hline & Permitir a participação mais ampla da sociedade \\
\hline
\end{tabular}

Fonte: Elaboração própria. 
Para fins de compreensão da análise construída, compartilhamos dois trechos de ações distintas, categorizados na pesquisa como indicadores do favorecimento da construção da Recomposição Investigativa e da Exposição Pública respectivamente:

No Laboratório de Educação, Cinema e Audiovisual, os encontros para planejar e avaliar as diferentes ações com cinema nos projetos permite aprofundar práticas alimentadas pelos seminários de pesquisa, cujas leituras e reflexões voltam para a prática no compartilhamento de materiais e dispositivos pedagógicos. ${ }^{4}$

Dessa maneira, pretendemos potencializar discussões sobre educação cidadã e produção da justiça cognitiva e social, promovendo uma formação continuada mais ecológica em relação aos saberes que circulam nos espaços de atuação do projeto. $^{5}$

Observamos indícios nestes extratos da articulação destes programas e projetos de extensão com grupos de pesquisa. Essa articulação, conduzida pelo próprio coordenador da ação, foi compreendida como potente meio para que professores em formação inicial tivessem oportunidade de incorporarem em sua rotina profissional uma dinâmica de pesquisa, de registrarem reflexões, acumularem conhecimentos e renovarem suas práticas. Já a o desenvolvimento da segunda posição foi relacionado à própria dinâmica da extensão em sua relação com a sociedade e, com isso, oferecer possibilidades para a construção de uma consciência crítica, política e social. Este aspecto observado mostrase de fundamental importância para uma formação além das competências por revelar a pesquisa como princípio cognitivo e formativo aliada a uma indissociabilidade entre ensino e extensão que imprime o papel do compromisso social, político e ético da formação docente.

Na sequência, trazemos trechos de documentos onde marcas da Interposição Profissional e da Composição Pedagógica se fizeram perceber nos programas e projetos que concebiam suas propostas de formação docente estreitamente articuladas com as escolas e os profissionais que nelas atuam, pela via da dialogicidade e do trabalho colaborativo.

O projeto que aqui se estrutura está voltado para a ampliação e potencialização da tessitura dessa Política e envolve a inserção de bolsistas no trabalho em sala de aula e a troca de experiências e

\footnotetext{
${ }^{4}$ FORMULÁRIO-SÍNTESE DA PROPOSTA - SIGProj, p. 06.

${ }^{5}$ FORMULÁRIO-SÍNTESE DA PROPOSTA - SIGProj, p. 05.
} 
os saberes experienciais como processos formativos enredados/imbricados na vida cotidiana apontando a - e com isso também atuando pela e para a desinvisibilização da complexidade que faz parte do processo de formação, que é contínuo. ${ }^{6}$

As marcas destas posições se expressaram através da proposição de momentos específicos das ações de extensão estudadas que seriam dedicados a proporcionar espaços e tempos para que o professor em formação inicial encontrasse sua maneira de ser professor com outros professores, em diálogo, e em pleno reconhecimento do papel formador dos professores das escolas. Valorizando o conhecimento profissional de outros professores, estas ações propunham momentos coletivos para julgar e decidir caminhos no dia a dia profissional, lidando com o conhecimento em situações de relação humana. Neste sentido, são ações que estabelecem relação direta com o trabalho, colocando-o como princípio educativo e formativo, bem como promovendo, no encontro com a escola e os professores em exercício, um caminho formativo capaz de transpor limites entre formação inicial e continuada.

Finalmente, a pesquisa apontou que foram encontrados indícios do favorecimento para o desenvolvimento da Disposição Pessoal em dois dos projetos analisados. Destacamos o trecho da proposta que nos remete a essa categoria: "Para isso, usamos uma metodologia que envolve a inserção de outros sujeitos no cotidiano da sala de aula com a perspectiva de que estes trabalhem junto aos professores"7. Compreendemos que ao inserir os estudantes do curso de Pedagogia em formação inicial na sala de aula do professor experiente é possível dar-lhe um primeiro conhecimento da profissão.

No trecho: "A segunda se dá por meio de encontros quinzenais de toda a equipe envolvida para discussão sobre o cotidiano escolar e as práticas pedagógicas vividas e por viver" ${ }^{\prime \prime}$, compreendemos a posição firmada pelo projeto, que, em função de espaços coletivos de autoconhecimento e autoconstrução, permite ao professor em formação inicial construir uma Disposição Pessoal com o auxílio de momentos e lugares de trocas, narradas por colegas de projeto e professores das escolas, em uma rede que articula formação inicial e formação continuada em confluência para a formação profissional docente, marcando assim espaços e tempos para o autoconhecimento e a autoconstrução enquanto momentos deliberadamente dedicados ao desenvolvimento da capacidade de relação e de comunicação, reconhecendo que o ensino é uma profissão do humano e do

\footnotetext{
${ }^{6}$ FORMULÁRIO-SÍNTESE DA PROPOSTA - SIGProj, p. 05.

${ }^{7}$ FORMULÁRIO-SÍNTESE DA PROPOSTA - SIGProj, p. 05.

${ }^{8}$ FORMULÁRIO-SÍNTESE DA PROPOSTA - SIGProj, p. 04.
} 
relacional. Diante disso, observamos, pela via da extensão universitária, a potencialidade em proporcionar vivências ancoradas no trabalho coletivo e interdisciplinar de forma reflexiva e problematizadora, como mais um aspecto favorável a uma formação de professores além da aplicação e das competências.

Foi possível constatar que as posições para a formação de professores (NÓVOA, 2017) com mais entrada nos programas e projetos analisados são a Recomposição Investigativa e a Exposição Pública, devido a articulação dos programas e projetos de extensão com grupos de pesquisa, e com a própria dinâmica da extensão em sua relação com a sociedade. Em seguida observamos marcas da Interposição Profissional e Composição Pedagógica em programas e projetos que concebem suas propostas de formação docente estreitamente articuladas com as escolas e os seus profissionais, pela via da dialogicidade e do trabalho colaborativo. Encontramos indícios de favorecimento ao desenvolvimento da Disposição Pessoal em dois projetos analisados, visto que suas propostas marcam em seus registros momentos para o primeiro conhecimento da profissão, bem como espaços e tempos para o autoconhecimento e a autoconstrução.

\section{Considerações finais}

Concluímos que as atividades de extensão universitária, dada a sua condição de elo de ligação entre universidade e sociedade por meio de um processo transformador, orgânico e integrado de educação, cultura e ciência, apresentam condições de proporcionar experiências formativas que articulem formação inicial, indução e formação em serviço de maneira que seu processo esteja amparado na investigação, colaboração, trabalho em equipe e acompanhamento distanciando-se assim do esvaziamento de sentidos de uma concepção pautada pela constituição de competências e habilidades técnicas tal como preconizam as resoluções CNE/CP n 2/2019 e nº 1/2020.

Os resultados desta pesquisa contribuem para o fortalecimento de nossa defesa a favor de uma formação de professores, no âmbito do curso de Pedagogia, comprometida com a docência em sua complexidade e não, exclusivamente, com as competências necessárias ao seu exercício. E, acreditamos que podemos encontrar na parceria entre universidade - escola básica - professores e sociedade um novo lugar institucional, responsável por formar professores, no qual a cultura profissional, a postura investigativa e a valorização dos saberes socialmente construídos são constitutivas e constituintes.

As ações de Extensão Universitária possuem elementos que favorecem a formação inicial de professores "na tensão interior das contingências" (ABREU, 2015, p. 63), ou seja, assume, diante da realidade social, os limites de uma formação tanto 
acadêmica quanto prática que se distancia das questões insurgentes da educação brasileira. Representam assim um caminho para a superação de uma cultura curricular instrumental e utilitária, tal qual vem sendo proposta pelas novas Diretrizes presentes na Resolução CNE/CP n. 2/2019.

\section{Referências}

ABREU, S. C. S. R. Universidade e Escola Básica: o papel da extensão universitária na formação de professoras e professores em educação científica. 2015. Tese (Doutorado em Educação). Universidade de São Carlos, São Paulo. Disponível em: https://sucupira.capes.gov.br/sucupira/public/consultas/coleta/trabalhoConclusao/viewT rabalhoConclusao.jsf?popup=true\&id_trabalho=3216955. Acessado em 17 de novembro de 2018.

BRASIL. Resolução CNE/CP n. 1/2006 de 15 de maio de 2006. Diário Oficial da União, $\mathrm{n}^{\circ}$ 92, seção 1, p.11 - 12, 16 maio 2006.

BRASIL. Resolução CNE/CP n. 2, de 20 de dezembro de 2019. Diário Oficial da União. Brasília, 2019.

BRASIL. Resolução CNE/CP n. 1, de 27 de outubro de 2020. Diário Oficial da União. Brasília, 2019.

DIAS, R. E.; LOPES, A. C. Competências na formação de professores no Brasil: o que (não) há de novo. Educação \& Sociedade, Campinas, v. 24, n. 85, p. 1155-1177, 2003.

DINIZ-PEREIRA, J. E. Nova tentativa de padronização dos currículos dos cursos de licenciatura no Brasil: a BNC-Formação. Revista Práxis Educacional, v. 17, n. 46, p. 119, JUL./SET. 2021. 2021. DOI: https://doi.org/10.22481/praxisedu.v17i46.8916

FÓRUM DE PRÓ-REITORES DE EXTENSÃO DAS INSTITUIÇÕES PÚBLICAS DE EDUCAÇÃO SUPERIOR BRASILEIRAS (FORPROEX). I Encontro Nacional de PróReitores de Extensão das Universidades Públicas Brasileiras. Conceito de extensão, institucionalização e financiamento. UNB, Brasília, 04 e 05 de novembro de 1987. Disponível em: https://www.ufmg.br/proex/renex/images/documentos/1987-I-EncontroNacional-do-FORPROEX.pdf. Acesso em agosto de 2017.

FÓRUM DE PRÓ-REITORES DE EXTENSÃO DAS INSTITUIÇÕES PÚBLICAS DE EDUCAÇÃO SUPERIOR BRASILEIRAS (FORPROEX). Política Nacional de Extensão Universitária. Manaus, Amazonas. Maio de 2012. Disponível em: https://www.ufmg.br/proex/renex/images/documentos/2012-07-13-Politica-Nacionalde-Extensao.pdf. Acesso em agosto de 2017.

FÓRUM DE PRÓ-REITORES DE EXTENSÃO DAS INSTITUIÇÕES PÚBLICAS DE EDUCAÇÃO SUPERIOR BRASILEIRAS (FORPROEX). Comissão Permanente de Avaliação da Extensão - CPAE. Avaliação da Extensão Universitária: práticas e 
discussões da Comissão Permanente de Avaliação da Extensão. Organização: Maria das Dores Pimentel Nogueira; textos: Sonia Regina Mendes dos Santos... [et al.] - Belo Horizonte: FORPROEX/CPAE; PROEX/UFMG, 2013, p. 51-74.

\section{INSTITUTO NACIONAL DE ESTUDOS E PESQUISAS EDUCACIONAIS ANÍSIO}

TEIXEIRA. Sinopse Estatística da Educação Superior 2016. Brasília: Inep, 2017. Disponível em: http://portal.inep.gov.br/basica-censo-escolar-sinopse-sinopse. Acesso em: $08 / 10 / 2018$.

LISTON, D. P. \& ZEICHNER, K. M. Teacher education and the social conditions of schooling. Routledge, New York, NY. 1991.

NÓVOA, A. Vidas de professores. 2. ed., Porto Editora, Porto, 1995.

NÓVOA, A. Professores: imagens do futuro presente. Lisboa: Educa, 2009.

NÓVOA, A. Firmar a posição como professor, afirmar a profissão docente. Cadernos de Pesquisa, 2017, vol.47, n.166, p.1106-1133.

PÉREZ GÓMEZ, A. Função e formação do professor/a no ensino para a compreensão: diferentes perspectivas. In: GIMENO SACRISTÁN, J.; PÉREZ GÓMEZ, A. Compreender e transformar o ensino. 4. ed. Porto Alegre: Artmed, 1998. p. 353-379.

PEREIRA, A. O curso de Pedagogia e as novas diretrizes curriculares: análise crítica de um currículo escrito. Espaço do Currículo, v. 7, n. 2, p. 297-313, mai-ago, 214.

PORTELINHA, A. M. S. As DCN 2019 para a formação de professores: tensões e perspectivas. Revista Práxis Educacional, v. 17, n. 46, p. 1-21, Jul./Set. 2021. 2021. DOI: https://doi.org/10.22481/praxisedu.v17i46.8925

SOUZA, ANA L. L. A História da Extensão Universitária. Campinas: Ed. Alínea, 2010.

ZEICHNER, K. Repensando as conexões entre a formação na universidade e as experiências de campo na formação de professores em faculdades e universidades. Educação, Santa Maria, v. 35, nº 3, p. 479-504, set./dez. 2010.

ZEICHNER, K.; SAUL, A.; DINIZ-PEREIRA, J. E. Pesquisar e Transformar a Prática Educativa: mudando as perguntas da formação de professores - uma entrevista com Kenneth Zeichner. Revista e-Curriculum, São Paulo, v. 12, nº 03 p. 2211 - 2224 out./dez. 2014.

ZEICHNER, K.; PAYNE, K.; \& BRAYKO, K. (in press). Democratizing teacher education. Journal of Teacher Education. 2015. Vol. 66 (2). p. 122 - 135. 
* Roberta Pereira de Paula Rodrigues é Pedagoga da Pró-reitoria de Extensão da Universidade Federal do Rio de Janeiro - UFRJ. Mestre em Educação pela UFRJ. Membro do Grupo de Estudos e Pesquisas em Didática e Formação de Professores - GEPED.

E-mail: robertapdepaularodrigues@gmail.com

Orcid: https://orcid.org/0000-0003-1687-7838

** Giseli Barreto da Cruz é professora da Faculdade de Educação da Universidade Federal do Rio de Janeiro, vinculada ao Programa de Pós-Graduação em Educação. Doutora em Educação pela Pontifícia Universidade Católica do Rio de Janeiro. Coordenadora do Grupo de Estudos e Pesquisas em Didática e Formação de Professores (GEPED/CNPq). Cientista do Nosso Estado pela FAPERJ.

E-mail: giselicruz@fe.ufri.com

Orcid: https://orcid.org/0000-0001-5581-427X 